\title{
Should School Boards Discontinue Support for High School Football?
}

Lewis H. Margolis, MD, MPH, ${ }^{a}$ Greg Canty, MD, ${ }^{b}$ Mark Halstead, MD, ${ }^{c}$ John D. Lantos, MD ${ }^{b}$

A pediatrician is asked by her local school board to help them decide whether to discontinue their high school football program. She reviews the available evidence on the risks of football and finds it hopelessly contradictory. Some scholars claim that football is clearly more dangerous than other sports. Others suggest that the risks of football are comparable to other sports, such as lacrosse, ice hockey, or soccer. She finds very little data on the long-term sequelae of concussions. She sees claims that good coaching and a school culture that prioritizes the health of athletes over winning can reduce morbidity from sports injuries. In this paper, 3 experts also review the evidence about sports risks and discuss what is known and not known about the science and the ethics of high school football.

Parents, pediatricians and school boards across the country are trying to decide whether high school football is so dangerous that football programs should be discontinued. Football is a collision sport. Some players will get concussions. But how high are the risks? Are there ways to keep kids safe even as they face those risks? We asked 3 experts about what pediatricians should be thinking and saying about the wisdom of continuing to support this very popular game.

\section{THE CASE}

A primary care pediatrician in a small town receives a phone call from the local school board asking her if she will come speak to them about the benefits and the risks of football for high school students. The board is worried because, during the recent high school football season, a newspaper reported about the experiences of 3 young men who sustained concussions while playing football. In the article, the reporter discussed ways that school athletic departments have tried to prevent concussions. He also discussed some of the longer-term consequences for the players covered in the story. The article stimulated conversations in the community and led to some pressure on the school board to discontinue high school football. At the same time, there was strong pressure on the board to continue the popular football program.

The local school board has requested advice in the face of this growing controversy surrounding high school football and concussions. Should the board and the school continue the high school football program? Or, if they discontinue football, should they discontinue other sports as well? What are the harms and benefits that the board should consider?

Lewis Margolis, MD, MPH, (University of North Carolina) Comment

Two factors-the football-specific risk of concussion and the prevalence of participation-motivate the question of whether to discontinue high school football. The sport-specific risk, calculated as cases per some measure of exposure (player, game, practice, or other defined event) is the highest

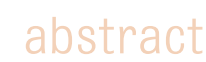

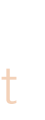


among all sports. A recent incidence study reported a concussion rate of 2.01 per 1000 athletic exposures for high school football, resulting in an estimated 79640 concussions (1 in 14 high school football players). ${ }^{1}$ According to Sports-Related Concussions in Youth: Improving the Science, Changing the Culture by the Institute of Medicine, high school football players have, by far, the highest risk of concussion of any sport. ${ }^{2}$ In football, the rate of concussion is $60 \%$ higher than in the second ranking sport, lacrosse. ${ }^{2}$ In terms of exposure or prevalence, over 1 million boys participate in football, compared with 100000 in lacrosse. ${ }^{3}$ The greater risk and the higher level of participation for football means that this one sport contributes far more concussions to our high school athletes than any other sport.

It is reasonable to ask what an "acceptable" risk of concussion might be. Such a risk could be derived from reviewing the distribution of risks for all sports or even all high school activities. A panel of experts, parents, and others committed to the well-being of adolescents could, perhaps, make a recommendation about an acceptable level. A similar process could address the as yet poorly understood longer-term risks, such as cognitive deficits or dementia. What is already known, however, both about the harm from concussions and repetitive head impacts and the contribution of football to the incidence, provokes the question of whether it is ethical to allow, not to mention encourage, adolescents to participate in the one sport that appears to make the greatest contribution to this medical and public health problem. High school football, as currently played, violates the 4 biomedical ethical principles of nonmaleficence, beneficence, respect for autonomy, and justice. ${ }^{4}$ These principles recognize the obligation of physicians to their patients, in this case the population of high school football players and their parents, and the community at-large, to provide their guidance and expertise on what is clearly a health problem.

\section{First, Do No Harm}

The hundreds of research studies analyzed by the Institute of Medicine, not to mention the multi-million dollar concussion settlement between the National Football League (NFL) and former players and between the National Collegiate Athletic Association (NCAA) and former players, bolster the argument that steps should be taken now to limit harm, not wait with uncertainty for additional research. The question is not whether football causes brain trauma. The question that research must try to answer is how much or how severe is the trauma caused by this sport, both acutely and, more importantly, long term. Knowing that football causes more harm to the brain than any other sport and yet encouraging participation while we await the results of more rigorous research violates the principle of do no harm.

\section{Second, Beneficence}

Football may provide benefits in character building, teamwork, and physical fitness, but given the potential long-term devastating harm, football does not meet the criterion of beneficence, because it is unknown whether the benefits exceed the risks. Other sports advance beneficence because they are less dangerous and still enhance character, teamwork, and physical fitness. Some may argue that motor vehicle crashes and bike crashes also result in concussions, but those risks of crashes are not ordinarily repetitive and the benefits of automobile and bike transportation are not as ambiguous as those for football.

\section{Third, Respect for Autonomy}

Although parents sign waivers for their sons to participate, the rigorous elements of informed consent or assent, fundamental to the principle of autonomy, are absent. True informed consent respects the autonomous decision-making capacity of participants by clearly explaining, among other points, the specific risks of concussion inherent in the sport, as well as the fact that the long-term consequences of participation are currently unknown. As is apparent from a recent report on tackling and football, pediatricians do not have the knowledge required to help parents "decide whether the potential health risks of sustaining these injuries (football-related) are outweighed by the recreational benefits associated with proper tackling." ${ }^{5}$ Even, however, if at some future point, the risks were explicit so that parents and their sons had the knowledge needed to make autonomous decisions, it is not appropriate for the school board to facilitate exposure to the risks of the serious harm to brains in football.

The violation of the fourth principle, justice, is perhaps the most troubling aspect of the ethical challenges posed by high school football. Specifically, the racial/ethnic and socioeconomic disparities in football participation are stunning. Although high school participation data by race/ethnicity are not available, according to the NCAA, in 2009 to 2010, for the first time African-American males composed the largest segment of college football players (45.8\%), with white players accounting for $45.1 \% .{ }^{6}$ The percentage of black players greatly exceeded their representation (13\%) in the overall population of the United States. This means that African-American football players face a disproportionate exposure to the risk of concussions and their consequences. Out of fairness, the community must ask whether those who participate in 
football are already at increased risk of poor health due to social determinants, such as race/ethnicity and socioeconomic status. This is not to make the patently unfair suggestion that African-American males or others at risk should be singled out from participation in football, but rather to acknowledge that acquiescence toward the risks of football disproportionately affects these populations.

This school board is deciding whether to discontinue high school football. One question they must ask is whether football can be made safer. A recent cohort study of the effects of the Heads Up Football coaching education program showed that injury rates could be reduced by encouraging different coaching techniques. In that study, however, there was no reduction in concussions. ${ }^{7}$ At present, there does not seem to be a way to reduce the number of head injuries in high school football.

There is no question that football is deeply imbedded in this community, as in US culture. Our society has, however, researched other harms, such as tobacco use, alcoholrelated driving, and obesity-related unhealthy diets and exercise, and successfully changed social norms. High school football violates the 4 basic bioethical principles. Pediatricians should advocate for the discontinuation of high school football programs until, and more importantly unless, we can be assured that it does not have longterm detrimental consequences.

\section{Greg Canty, MD, (Children's Mercy Kansas City) Comment}

I hope that this scenario about youth sports safety is playing out all across America as the fall sporting season begins. Educated professionals and community leaders should be discussing the many benefits and potential risks of sports participation. We should be absolutely committed to making sports as safe as possible for our children. As pediatricians, we need to make sure we are involved in this discussion.

This particular case highlights football. Because of the current controversies surrounding concussion, football is at the forefront of that concern about safety. Football has the highest incidence of sportsrelated concussion.

Football has always been a dangerous sport. Conversations about the safety of football have been taking place at kitchen tables for generations. It is a collision sport that is clearly not for everyone. We have always known about football's increased risk of fractures and musculoskeletal injuries. Those concerns now seem overshadowed by the topic of concussion.

As far back as the early 1900s, there have been rumblings about abolishing football. President Theodore Roosevelt, a football fan who wanted to save the sport, formed a safety council in 1906 that would go on to become the foundation of the NCAA. In 1969, the National Operating Committee on Standards for Athletic Equipment was formed and later developed a safety standard for football helmets in 1973. The efforts of the National Operating Committee on Standards for Athletic Equipment have been effective in decreasing skull fractures, intracranial bleeds, and deaths from head injury, but helmets were not previously designed to prevent concussion.

Football may be getting more dangerous. The Centers for Disease Control reports a 10 -fold increase in reported rates of sports-related concussions over the past decade. Most suspect that this increase in diagnoses is related to better awareness rather than a true increase in the incidence of concussion, but we do not know definitively.
This lack of data is pervasive. One of the challenges for medical professionals is separating the facts and the fear regarding concussion. Many practicing pediatricians were never educated on concussion. We are constantly barraged with media stories about former athletes, sporting organizations, and legal battles surrounding the topic. The movie "Concussion" catalyzed more discussions. As trusted physicians, we have to take concerns seriously. We should also push for more facts.

One fact is inarguable: concussion was ignored by far too many for far too long, including medical professionals. As a result, we are scrambling for better science to catch up with the media reports. Our understanding of the science and pathophysiology behind concussion remains limited. We do not know much about the implications of these head injuries in young athletes, but better reporting and better follow-up should help answer some of the questions about long-term consequences. Thankfully, an influx of grant funding and dedicated scientists are pushing this science forward, but we remain in the infancy stages.

One problem is that there are no definitive criteria for diagnosing a concussion. Headlines are about objective measurements like blood markers, functional MRIs, and neurocognitive testing, but as of 2016, clinicians are still left to diagnose concussion based on subjective measures like headache, dizziness, and numerous other nonspecific symptoms.

There are also no proven treatments. We lack any proven pharmacologic intervention and rely mostly on the tincture of time for management. Our return-to-sport strategies are based on consensus statements and lack scientific rigor.

As a sports medicine physician, I worry daily about the possible 
long-term implications of concussion including neurodegenerative diseases, chronic traumatic encephalopathy (CTE), mental health, etc. Although, once again, the science behind these potential associations remains unclear. CTE generates a lot of publicity, but even among professional athletes, it is very rare. It has been found in a hundred or so deceased athletes when the sample size of former athletes is in the millions. We have no idea how to apply current information about CTE to youth or living athletes. We have concerns, but no definitive answers.

One underappreciated issue in reports of CTE is that many athletes have other comorbid conditions and many of these conditions are treatable. Athletes, like the rest of us, suffer from depression, mental illness, headache disorders, and burnout. The subjective symptoms often overlap with those of concussion. When I read of athletes committing suicide, I immediately wonder whether they had been correctly diagnosed and treated. We may be misdiagnosing some treatable conditions as concussion-related. Concussion is a serious diagnosis, but it does not necessarily lead to longterm problems. When recognized and managed properly, most young athletes recover clinically within 3 weeks. It is likely (although, as I say, unproven) that there are no longterm consequences from a single concussion. The rush to doom and gloom scenarios may actually be harming patients.

Whenever we talk of restricting sports participation, the first question I ask is, does evidence clearly show that the risks outweigh the benefits? Coaches and former football players speak of how football prepared them for life by having the opportunity to work as a team, play a defined role, and interact with others from different backgrounds. Previous studies have shown many benefits of sports participation, including increased physical activity, improved self-confidence, more life satisfaction, better peer relations, and improved academic performance. None of these benefits are unique to football, but many athletes and their families readily embrace the sport.

Make no mistake; people do embrace football despite the recent concerns about safety. Football remains by far the most popular high school sport for boys. Last year, 1.1 million high school boys played. That is double the next closest sport. In youth leagues for ages 6 to 12 years, there was a drop off in tackle participants from 2008 to 2015, but recent numbers appear to be holding steady. As a nation, the annual Harris Poll has found professional football to be the most popular sport since 1985 , and it is followed closely by college football in the third position. In many communities, football essentially "owns" 3 days of the week during the fall: Friday nights (high school), Saturdays (college), and Sundays (NFL professional).

The public debate regarding concussion and sports safety is too focused on banning football. We need to remember the large increases in concussion have been seen across all sports, including soccer, hockey, and basketball. It extends across gender lines into female sports where the incidence may be even higher. If we eliminate football, what sport is next and what is our threshold? Who is going to be responsible for defining "safe play?"

Rather than limiting opportunities, I encourage pediatricians to look for ways to make all sports safer for our patients. Start by demanding certified athletic trainers at all sporting events. Be a resource for educating your community on sporting topics. Request more sports medicine opportunities during medical training. Volunteer to serve as an advisor for youth sporting organizations and schools. Make sure that concussion guidelines are strictly followed. Inform your patients and parents about what is known and what is not. But as long as your patients are playing, stay involved in the game!

\section{Mark Halstead, MD, (Washington University) Comment}

When I hear schools want to discontinue sports, I can become disheartened. As a sports medicine physician, I know the many benefits of participating in sports. Such benefits include developing skills of teamwork, learning leadership skills, understanding how to deal with adversity and challenges, practicing good sportsmanship, and, of course, the benefits of physical activity.

There are many reasons why a school may want to discontinue a sport. These include financial struggles, lack of interest of students, liability concerns, or gender equity (Title IX) issues, to name a few. We are often a reactionary society and only try to figure out what to do after a perceived or actual problem has developed. We do not always seek out proactive solutions to potential problems or challenges that may arise. I also see this in discussions involving high school athletics. For example, schools may not consider the purchase of an automated external defibrillator for their athletic venues until something happens to a student-athlete or a spectator at an event, despite evidence of the benefit to saving a life that timely access to a defibrillator can afford.

There are many good, proactive ways to lessen the health consequences of concussions. Schools should have a licensed athletic trainer on site, develop an emergency action plan, and, most importantly, practice that plan with the relevant individuals. There should be a physician who is knowledgeable about concussions at every football game. Schools should provide education for athletes, their families, and the coaching staffs. School policies regarding follow-up 
and return to play and the classroom after a concussion should be clear and publicized. All are part of the biggest task of all, creating a culture where teachers, athletes, coaches, parents, and school administrators take the injury seriously and encourage reporting of the injury. Young athletes who continue to play after their injury have worse symptoms and often take longer to recover than those who stop participation after their injury. Early reporting of a suspected concussion can help get the process rolling toward proper injury evaluation and management.

The decision facing the school board is tricky. Football garners much attention these days concerning concussions, but the injury is not unique or exclusive to that sport. Several studies demonstrate that ice hockey, boys lacrosse, wrestling, and girls soccer all have concussion rates rivaling and, in some cases, exceeding that of football. ${ }^{8-10}$ So if football is to be discontinued because of concussion concerns, we need to bring other sports to the table in that discussion if we are going to be fair. In fact, the majority of sports that are played in high school have some risk of concussion.

In recent years, we have seen the NFL, the NCAA, and several states now mandating reduced contact time in practices throughout the football season. Because we are never going to eliminate concussions from sports, a proactive approach to reducing contact practice time is a logical step. There has also been interest in promoting more flag football before high school to also reduce contact exposure at younger ages. This makes sense. Flag football for younger children can help them develop skills and appreciate the sport.

Personally, I feel that the pendulum of public opinion may have swung too far. Several decades ago, we did not have enough knowledge or concern about concussions and their consequences. Today, we have greater medical knowledge, but less general public understanding about the meaning of concussions. Some media reports suggest that even a single concussion may cause longterm brain damage. Ten years ago, my discussions with families often revolved around explaining why it is important to keep an athlete out from sports after a concussion, especially if he or she was still having symptoms. At that time, there was significant push back from both the athletes and the families regarding those recommendations. Now I often spend a lot of time during clinic visits trying to explain to families that it is okay for that young athlete to return to the sport after they have fully recovered from their single concussion. I spend a lot of time addressing many fears and misconceptions that families have regarding concussions.

We need to swing that pendulum back toward the middle with appropriate concern about the advances that have been made in knowledge about concussions and even the long-term consequences of concussions.

I am often asked if I would allow either of my 2 sons to play football knowing what I do about concussions. Yes, I would. But I qualify that yes by stating that it also has to be in an environment where the coaches are interested and care about developing kids' skills and their love of the sport. I would only let them play in a program that encourages safety and puts an athlete's health above winning. If those conditions did not exist, then my sons would be looking elsewhere for their athletic pursuits.

I am fortunate to volunteer for a high school with a head football coach who has created a culture of reporting injuries, particularly concussions, and who will keep a player out of a game if the player has been injured. The coach does this, sometimes, even if I am present and have evaluated the player and determined that he may safely return to play. This coach is passionate about winning, but he values his players' health above the game. I love that about him and see him as a model for other programs. If we could replicate that attitude and culture to all high schools and all teams, then discussions and concerns about discontinuing sports would not be on our radar. In such sports cultures, caring about our young athletes' health is, as it should be, the highest priority. Unfortunately, I do not think this is the case everywhere in youth sports today.

So I would not recommend discontinuing high school football. Instead, I would recommend that the board be proactive and seek out ways to keep our young athletes safe and reduce the risk of concussion because it is improbable to eliminate them. Schools should do that before a season starts and before the first injury, which is inevitable, happens.

\section{John D. Lantos, MD, (Children's Mercy Kansas City) Comment}

Decisions about sports participation, like decisions about medical treatment, can only be made with good facts. But it is tough to get the facts right. As our commenters point out, some studies say that football has the highest rate of concussion of any sport. Others suggest that men's ice hockey and lacrosse or women's soccer have comparable concussion rates. What is a parent or a school board member to do? The question ultimately comes down to one of risks and benefits. Can the benefits of football (or other risky sports) be achieved in less risky sports? I think that they can, so, if called by a school board, I would recommend that resources should be redirected from football programs to safer sports.

But I doubt that I would prevail. In spite of publicity about the dangers of football, the sport remains popular. More high school students participate 
in football than in any other sport. And many experts in sports medicine believe that football can be made safe enough. Given that, pediatricians should try to help parents and school boards understand the facts. They should also insure that a culture of safety prevails over a culture of winning at any cost.

\section{ABBREVIATIONS}

CTE: chronic traumatic encephalopathy

NCAA: National Collegiate Athletic Association NFL: National Football League

\section{REFERENCES}

1. Dompier TP, Kerr ZY, Marshall SW, et al. Incidence of concussion during practice and games in youth, high school, and collegiate American football players. JAMA Pediatr. 2015;169(7):659-665

2. Institute of Medicine and National Research Council. (NRC). SportsRelated Concussions in Youth: Improving the Science, Changing the Culture. Washington, DC: The National Academies Press; 2013

3. National Federation of State High School Associations. High school sports participation increases for 24th consecutive year. Available at: www.nfhs.org/content. aspx?id=9628. Accessed November 1, 2013

4. Beauchamp T, Childress J. Principles of Biomedical Ethics, 5th ed. 0xford, United Kingdom: Oxford University Press; 2001

5. Meehan WP, Landry GL; COUNCIL ON SPORTS MEDICINE AND FITNESS. Tackling in youth football. Pediatrics. 2015;136(5). Available at: http:// pediatrics.aappublications.org/ content/136/5/e1419
6. ESPN. Blacks now a majority on football teams. Available at: http:// www.espn.com/college-sports/news/ story? $\mathrm{id}=5901855$. Accessed 0ctober 31, 2016

7. Kerr ZY, Yeargin S, Valovich McLeod TC, et al. Comprehensive coach education and practice contact restriction guidelines result in lower injury rates in youth American football. Orthop J Sports Med. 2015;3(7):2325967115594578

8. Kontos AP, Elbin RJ, Sufrinko A, et al. Incidence of concussion in youth ice hockey players. Pediatrics. 2016;137 (2):e20151633

9. Rosenthal JA, Foraker RE, Collins CL, Comstock RD. National High School Athlete Concussion Rates From 20052006 to 2011-2012. Am J Sports Med. 2014;42(7):1710-1715

10. Marar M, Mcllvain NM, Fields SK, Comstock RD. Epidemiology of concussions among United States high school athletes in 20 sports. Am J Sports Med. 2012;40(4):747-755 


\section{Should School Boards Discontinue Support for High School Football? Lewis H. Margolis, Greg Canty, Mark Halstead and John D. Lantos Pediatrics 2017;139;}

DOI: 10.1542/peds.2016-2604 originally published online December 5, 2016;

\begin{tabular}{|c|c|}
\hline $\begin{array}{l}\text { Updated Information \& } \\
\text { Services }\end{array}$ & $\begin{array}{l}\text { including high resolution figures, can be found at: } \\
\text { http://pediatrics.aappublications.org/content/139/1/e20162604 }\end{array}$ \\
\hline References & $\begin{array}{l}\text { This article cites } 6 \text { articles, } 1 \text { of which you can access for free at: } \\
\text { http://pediatrics.aappublications.org/content/139/1/e20162604\#BIBL }\end{array}$ \\
\hline Subspecialty Collections & $\begin{array}{l}\text { This article, along with others on similar topics, appears in the } \\
\text { following collection(s): } \\
\text { Ethics/Bioethics } \\
\text { http://www.aappublications.org/cgi/collection/ethics:bioethics_sub } \\
\text { Sports Medicine/Physical Fitness } \\
\text { http://www.aappublications.org/cgi/collection/sports_medicine:physi } \\
\text { cal_fitness_sub } \\
\text { Concussion } \\
\text { http://www.aappublications.org/cgi/collection/concussion_sub }\end{array}$ \\
\hline Permissions \& Licensing & $\begin{array}{l}\text { Information about reproducing this article in parts (figures, tables) or } \\
\text { in its entirety can be found online at: } \\
\text { http://www.aappublications.org/site/misc/Permissions.xhtml }\end{array}$ \\
\hline Reprints & $\begin{array}{l}\text { Information about ordering reprints can be found online: } \\
\text { http://www.aappublications.org/site/misc/reprints.xhtml }\end{array}$ \\
\hline
\end{tabular}




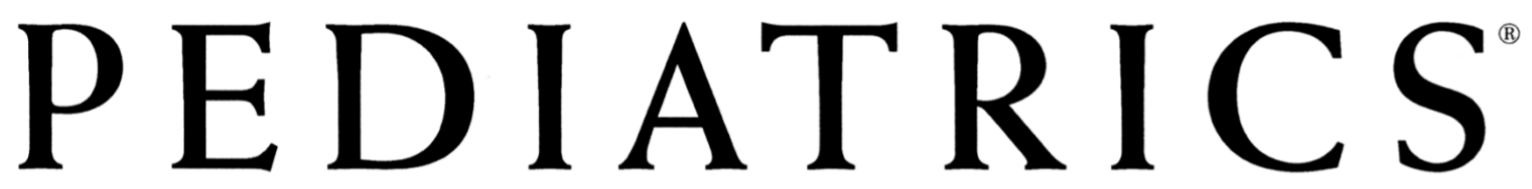

OFFICIAL JOURNAL OF THE AMERICAN ACADEMY OF PEDIATRICS

Should School Boards Discontinue Support for High School Football?

Lewis H. Margolis, Greg Canty, Mark Halstead and John D. Lantos

Pediatrics 2017;139;

DOI: 10.1542/peds.2016-2604 originally published online December 5, 2016;

The online version of this article, along with updated information and services, is located on the World Wide Web at:

http://pediatrics.aappublications.org/content/139/1/e20162604

Pediatrics is the official journal of the American Academy of Pediatrics. A monthly publication, it has been published continuously since 1948. Pediatrics is owned, published, and trademarked by the American Academy of Pediatrics, 141 Northwest Point Boulevard, Elk Grove Village, Illinois, 60007. Copyright $\odot 2017$ by the American Academy of Pediatrics. All rights reserved. Print ISSN: 1073-0397. 